\title{
Determinants of brain tumor malpractice litigation outcome and indemnity payments: a 29-year nationwide analysis
}

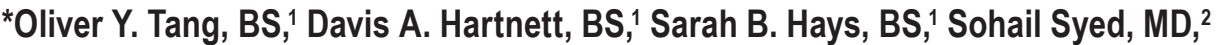 \\ and Alan H. Daniels, MD³
}

${ }^{1}$ The Warren Alpert Medical School of Brown University, Providence; and Departments of ${ }^{2}$ Neurosurgery and ${ }^{3}$ Orthopedics, Rhode Island Hospital, Providence, Rhode Island

\begin{abstract}
OBJECTIVE Medical malpractice litigation is a significant challenge in neurosurgery, with more than $25 \%$ of a neurosurgeon's career on average spent with an open malpractice claim. While earlier research has elucidated characteristics of litigation related to brain tumor treatment, factors impacting outcome and indemnity payment amount are incompletely understood.

METHODS The authors identified all medical malpractice cases related to brain tumors from 1988 to 2017 in VerdictSearch, a database of 200,000 cases from all 50 states. The outcome for each case was dichotomized from the perspective of the defendant physician as favorable (defendant victory) or unfavorable (plaintiff victory or settlement). Indemnity payments were recorded for cases that resulted in settlement or plaintiff victory. Univariate regression was used to assess the association between case characteristics and case outcome as well as indemnity payment amount. Subsequently, significant variables were used to generate multivariate models for each outcome. Statistical significance was maintained at $p<0.05$.
\end{abstract}

RESULTS A total of 113 cases were analyzed, resulting most commonly in defendant (physician) victory (46.9\%), followed by settlement and plaintiff victory (both $26.5 \%$ ). The most common specialty of the primary defendant was neurosurgery (35.4\%), and the most common allegation was improper diagnosis (59.3\%). Indemnity payments totaled $\$ 191,621,392$, with neurosurgical defendants accounting for $\$ 109,000,314(56.9 \%)$. The average payments for cases with a plaintiff victory $(\$ 3,333,654)$ and for settlements $(\$ 3,051,832)$ did not significantly differ $(p=0.941)$. The highest rates of unfavorable outcomes were observed among radiologists $(63.6 \%)$ and neurosurgeons $(57.5 \%)(p=0.042)$. On multivariate regression, severe disability was associated with a lower odds of favorable case outcome (OR $0.21, p=$ 0.023), while older plaintiff age (> 65 years) predicted higher odds of favorable outcome (OR 5.75, $p=0.047$ ). For 60 cases resulting in indemnity payment, higher payments were associated on univariate analysis with neurosurgeon defendants $(\beta$-coefficient $=2.33, p=0.017)$, whether the plaintiff underwent surgery $(\beta$-coefficient $=2.11, p=0.012)$, and the plaintiff experiencing severe disability $(\beta$-coefficient $=4.30, p=0.005)$. Following multivariate regression, only medical outcome was predictive of increased indemnity payments, including moderate disability $(\beta$-coefficient $=4.98, p=0.007)$, severe disability $(\beta$-coefficient $=6.96, p=0.001)$, and death $(\beta$-coefficient $=3.23, p=0.027)$.

CONCLUSIONS Neurosurgeons were the most common defendants for brain tumor malpractice litigation, averaging more than $\$ 3$ million per claim paid. Older plaintiff age was associated with case outcome in favor of the physician. Additionally, medical outcome was predictive of both case outcome and indemnity payment amount.

https://thejns.org/doi/abs/10.3171/2020.8.FOCUS20601

KEYWORDS brain tumor surgery; neurosurgery; medical malpractice; litigation; VerdictSearch

$\mathrm{B}$ RAIN tumor-related malpractice litigation is an area that warrants study due to the increasing incidence documented for several brain tumor subtypes, driven by the expansion of noninvasive imaging modalities. ${ }^{4,6}$ Additionally, while spinal procedures make up the major- ity of neurosurgery-related malpractice claims, the average indemnity payment for cranial procedures is approximately $\$ 100,000$ higher. $^{7}$ The malpractice environment for brain tumors may also be influenced by the multidisciplinary nature of the care process, incorporating primary care

ABBREVIATIONS NPDB $=$ National Practitioner Data Bank. SUBMITTED June 30, 2020. ACCEPTED August 19, 2020. INCLUDE WHEN CITING DOI: 10.3171/2020.8.FOCUS20601. ${ }^{*}$ O.Y.T., D.A.H., and S.B.H. contributed equally to this work. 
physicians, radiologists, neurologists, and neurosurgeons. Finally, malpractice may impact access to care, as $45 \%$ of neurosurgeons have reported removing high-risk procedures, such as tumor resection, from their practice due to concerns over litigation. ${ }^{8}$

Medical malpractice litigation is a significant challenge for neurosurgery due to the high disease severity and intensive care process for neurosurgical patients. In general, $7.4 \%$ of physicians in the United States face a malpractice claim annually, with $1.6 \%$ of these claims leading to indemnity payment. ${ }^{1}$ In contrast, $19.1 \%$ of neurosurgeons face a claim annually, and an estimated $99 \%$ of neurosurgeons will have faced at least one claim by the age of 65 years. ${ }^{1}$ Approximately $27.2 \%$ of a neurosurgeon's career is spent with an open, unresolved malpractice claim. ${ }^{2}$ Due to the sharp growth in costs documented for neurosurgery, ${ }^{3}$ a concerning consequence of malpractice litigation is an increased reliance on defensive medicine, the administration of extraneous diagnostic tests, or interventions to protect a physician against a potential malpractice claim, which is estimated to drive an additional $\$ 60$ billion in healthcare expenditures across all specialties annually. ${ }^{4}$ Moreover, these figures also do not reflect the indirect costs of litigation on a neurosurgeon, including added work, stress, reputational damage, and burnout. ${ }^{5}$

Amid these considerations, earlier research has evaluated characteristics of malpractice litigation for brain tumors, ${ }^{9,10}$ but no study has investigated determinants impacting case outcome or indemnity payment amount for these cases. Consequently, this was the goal of the present analysis.

\section{Methods \\ Data Sources}

We retrospectively analyzed medical malpractice cases from January 1989 to December 2017 in the VerdictSearch legal database (ALM Media Properties, LLC), which curates more than 200,000 cases from all 50 states and is updated daily. The VerdictSearch database has been employed by several earlier studies of malpractice litigation and surgical procedures. ${ }^{11-19}$ The criteria used by VerdictSearch to include cases is not publicly available. Medical malpractice cases were queried using the Boolean search criteria "brain" and ("tumor" OR "cancer" OR "malignancy") in the malpractice case subcategory. Due to the high level of qualitative case description, using synonymous search criteria including variants of "neurologic" or specific brain tumor subtypes did not increase returned results. All cases related to the diagnosis, management, or surgical intervention of a brain tumor were included for analysis.

Recorded data from each case included litigation outcome of the case, the field of the defending physician, whether the patient underwent surgery, medical outcome, allegation, tumor type, and age group. The three possible litigation outcomes were defendant (physician) victory, plaintiff (patient) victory, or settlement. In the case of plaintiff victory or settlement, the indemnity payment amount was also recorded. Defendant fields were classified as neurosurgeon, primary care physician, radiologist, or other. Medical outcome was classified using a criteri- on determined a priori as mild disability (self-resolving impairment), moderate disability (persistent impairment with functional loss), severe disability (persistent impairment involving inability to return to work, visual changes, loss of limb movement, or loss of language), death, or other (emotional distress, negligence in care, or no noted sequelae). Plaintiff allegation was categorized as improper diagnosis, improper treatment decision, or operative injury. Tumor type was categorized as benign, malignant, or unspecified (if there was insufficient detail to classify between benign or malignant). Data collection was independently performed by two authors (D.A.H. and S.B.H.). Interauthor disagreement on data categorization was uncommon $(<5 \%)$, with all instances resolved by a more senior author (S.S.).

We analyzed national trends in medical malpractice litigation using the National Practitioner Data Bank (NPDB), an online repository of medical malpractice payments and adverse action reports. ${ }^{20}$ The NPDB was first established by Congress in 1986 and mandates the reporting of these data from healthcare entities, including state licensing boards, hospitals, and insurance companies. The annual number of medical malpractice payment reports and practicing physicians for all 50 states was obtained, beginning in 1991, the first complete year of data within the NPDB's Data Analysis Tool. To adjust geographic differences in malpractice reports for the concentration of practicing physicians, we calculated a malpractice/physician rate for each US Census region that equaled the number of malpractice reports divided by the number of practicing physicians. ${ }^{11}$ We compared the volume of malpractice reports and geographic distribution (by the 4 US Census regions) between all cases overall (NPDB) and brain tumor cases specifically (VerdictSearch). Due to the public availability of both databases, this study was exempt from institutional review board approval.

\section{Statistical Analysis}

All analyses were performed using Stata 14 (StataCorp, LLC). Descriptive statistics were first generated. We subsequently analyzed two primary endpoints: litigation outcome for the physician and level of indemnity payment. Litigation outcome for the physician was dichotomized into favorable (defendant victory) or unfavorable (settlement or plaintiff victory). Because there were no indemnity payments for cases with a defendant victory, only cases resulting in a settlement or plaintiff victory were considered for analyses involving indemnity payment. All indemnity payments were adjusted for inflation to 2017 US dollars using the Consumer Price Index. Differences in outcome across case characteristic categories were analyzed using Fisher's exact test for litigation outcome and the nonparametric Mann-Whitney U-test for indemnity payment level. Subsequently, we performed univariate regression to evaluate the association between case characteristics and litigation outcome or indemnity payment level. All variables that were significant on univariate analysis were subsequently used for a multivariate model predicting litigation outcome or indemnity payments. For litigation outcome, logistic regression was used and odds ratios are reported. For indemnity payment level, 
TABLE 1. Overall characteristics of brain tumor malpractice cases

\begin{tabular}{|c|c|}
\hline Characteristic & No. of Cases (\%) \\
\hline Total & $113(100.0)$ \\
\hline \multicolumn{2}{|l|}{ Case outcome } \\
\hline Defendant & $53(46.9)$ \\
\hline Settlement & $30(26.5)$ \\
\hline Plaintiff & $30(26.5)$ \\
\hline \multicolumn{2}{|l|}{ Field of primary defendant } \\
\hline Neurosurgeon & $40(35.4)$ \\
\hline Primary care physician & $34(30.1)$ \\
\hline Radiologist & $11(9.7)$ \\
\hline Other & $28(24.8)$ \\
\hline Underwent surgery & $48(42.5)$ \\
\hline \multicolumn{2}{|l|}{ Medical outcome } \\
\hline Mild disability & $21(18.6)$ \\
\hline Moderate disability & $33(29.2)$ \\
\hline Severe disability & $24(21.2)$ \\
\hline Death & $30(26.5)$ \\
\hline Other & $5(4.4)$ \\
\hline \multicolumn{2}{|l|}{ Allegation } \\
\hline Improper diagnosis & $67(59.3)$ \\
\hline Improper treatment decision & $24(21.2)$ \\
\hline Operative injury & $22(19.5)$ \\
\hline \multicolumn{2}{|l|}{ Tumor type } \\
\hline Benign & $60(53.1)$ \\
\hline Malignant & $8(7.1)$ \\
\hline Unspecified & $45(39.8)$ \\
\hline \multicolumn{2}{|l|}{ Age group, yrs } \\
\hline Pediatric, 0-17 & $19(16.8)$ \\
\hline Adult, 18-64 & $83(73.5)$ \\
\hline Senior, $\geq 65$ & $11(9.7)$ \\
\hline \multicolumn{2}{|l|}{ Census region } \\
\hline Northeast & $40(35.4)$ \\
\hline Midwest & $23(20.4)$ \\
\hline South & $27(23.9)$ \\
\hline West & $23(20.4)$ \\
\hline
\end{tabular}

Some percentages may not add up to $100 \%$ due to rounding.

we used a generalized linear model with a gamma link distribution and log link function, which is idealized for modeling continuous right-skewed outcomes, such as payment following litigation. This regression model reported $\beta$-coefficients corresponding to a multiplicative change in outcome. For example, a $\beta$-coefficient $=1.75$ denotes a 1.75 -fold increase in indemnity payments or a $75 \%$ increase. Statistical significance was maintained at $\mathrm{p}<0.05$.

\section{Results}

\section{Characteristics of Brain Tumor Malpractice Cases}

We analyzed a total of 113 cases related to the management of brain tumors from 1989 to 2017 (Table 1 and
Supplementary Table 1). The year 2000 had the highest number of cases $(n=13)$, but there was no clear change in the frequency of cases across the study period (Fig. 1A). The verdict was in favor of the defendant in $46.9 \%$ $(\mathrm{n}=53)$, in favor of the plaintiff in $26.5 \%(\mathrm{n}=30)$, and a settlement in $26.5 \%$ ( $\mathrm{n}=30$ ). The most common defendant field was neurosurgery (35.4\%), followed by primary care $(30.1 \%$; Fig. 1B). Plaintiffs most frequently alleged improper diagnosis $(59.3 \%)$, followed by improper treatment decision (21.2\%) and operative injury (19.5\%). The majority of plaintiffs had a benign tumor (53.1\%) and were between 18 and 64 years of age (73.5\%).

Among the 60 cases with a plaintiff victory or settlement, the cumulative level of indemnity payments was $\$ 191,621,392$. The total payment from neurosurgical defendants was $\$ 109,000,314$, or $56.9 \%$, of all indemnity payments. Half of all cases had a payment under \$2 million, but in two cases, payment exceeded $\$ 19$ million (Fig. 1C). For both cases, a neurosurgeon was the primary defendant, and the plaintiff alleged operative injury, with one instance involving significant postoperative edema that was missed on follow-up imaging and the other involving postoperative stroke due to injury of a major artery. Although the average payment for cases with a plaintiff victory $(\$ 3,333,654$; standard error $\$ 714,254)$ was higher than that for settlements $(\$ 3,051,832$; standard error $\$ 821,527)$, this difference was not statistically significant ( $p=0.941$; Fig. 1D).

The cases occurred in 20 unique states, with the most commonly represented states being New York $(\mathrm{n}=25$, $22.1 \%)$, California $(n=21,18.6 \%)$, and Michigan $(n=14$, $12.4 \%$ ). Compared with the fluctuation of brain tumor case frequency across years, the number of total malpractice reports nationwide in the NPDB declined steadily, from 19,016 in 1991 to 11,596 in 2017 (Fig. 2A). The regional distribution of all cases and brain tumor cases was similar, with the Northeast (32.2\% of all cases vs $35.4 \%$ of brain tumor cases) and South (30.2\% of all cases vs $23.9 \%$ of brain tumor cases) being the two predominant regions (Fig. 2B). This trend remained after adjustment for the number of practicing physicians in each region, and the malpractice/physician rate was $4.91 \%$ for the Northeast, $4.36 \%$ for the South, $4.03 \%$ for the West, and $3.01 \%$ for the Midwest (Fig. 2C). Like brain tumor cases in VerdictSearch, the most represented state for overall malpractice reports in the NPDB was New York $(n=58,759)$, followed by California $(\mathrm{n}=50,692)$.

\section{Association Between Case Characteristics and Litigation Outcome}

There were significant differences in the plaintiff allegation depending on the field of the defending provider $(\mathrm{p}<0.001)$, with neurosurgeons receiving the majority of allegations regarding improper treatment decision (79.2\%) and operative injury (77.3\%), but the minority of allegations related to improper diagnosis $(6.0 \%$; Supplementary Fig. 1). Litigation outcome also varied significantly based on defendant field, with the highest rate of unfavorable outcomes (settlement or plaintiff victory) seen for radiologists (63.6\%) and neurosurgeons (57.5\%) $(\mathrm{p}=0.042$; Fig. 3A). While higher rates of unfavorable ligation outcomes for defendants were also observed if plaintiffs underwent sur- 

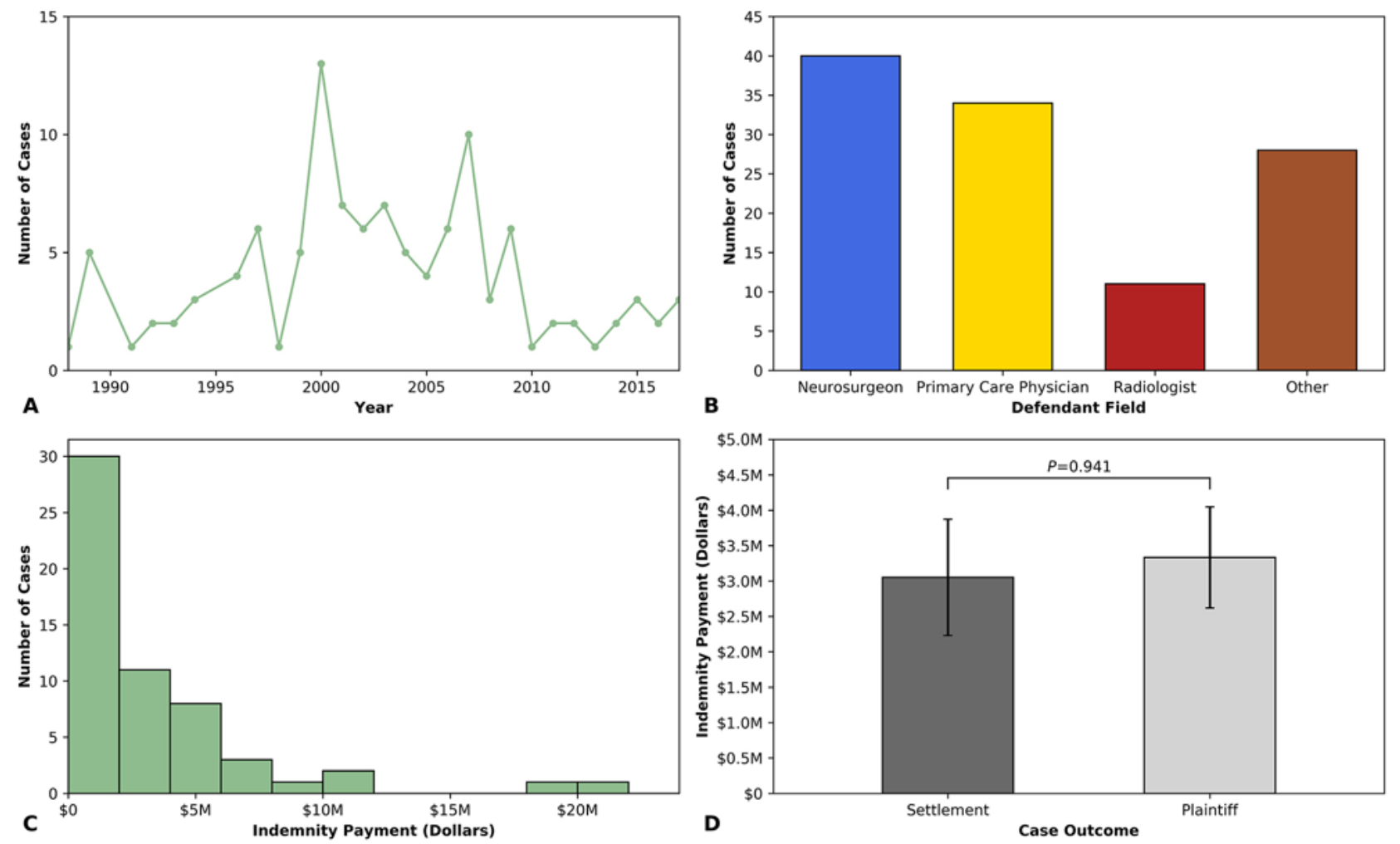

FIG. 1. Characteristics of brain tumor malpractice cases from 1988 to 2017. A: Number of cases annually in the VerdictSearch database from 1988 to 2017. B: Breakdown of field for the physician serving as the primary defendant for brain tumor malpractice litigation. C: Histogram of level of indemnity payment for cases resulting in a settlement or plaintiff victory $(n=60)$. D: Comparison of average indemnity payment for cases resulting in a settlement compared with a plaintiff victory. Significant differences in mean cost were determined using a nonparametric Mann-Whitney U-test.

gery $(54.2 \%)$ and experienced severe disability $(75.0 \%)$ or death $(50.0 \%)$, these differences did not reach significance (Fig. 3B and C). Furthermore, no significant differences in litigation outcome were observed based on allegation or tumor type (Fig. 3D and E). However, litigation outcomes did vary significantly based on age group $(p=0.035)$, with cases involving pediatric plaintiffs having the highest rates of unfavorable outcome $(68.4 \%)$ and those involving senior plaintiffs having the lowest (27.2\%; Fig. 3F).
For univariate regression, the plaintiff experiencing a severe disability was associated with significantly lower odds of a favorable outcome (OR $0.25, \mathrm{p}=0.032$ ), while the plaintiff being 65 years or older was associated with higher odds of a favorable outcome (OR 5.78, $\mathrm{p}=0.036)$ (Table 2). Defendant specialty, performance of surgery, allegation, and tumor type were not predictive of the case outcome. Following multivariate regression including medical outcome and plaintiff age group, severe disabil-
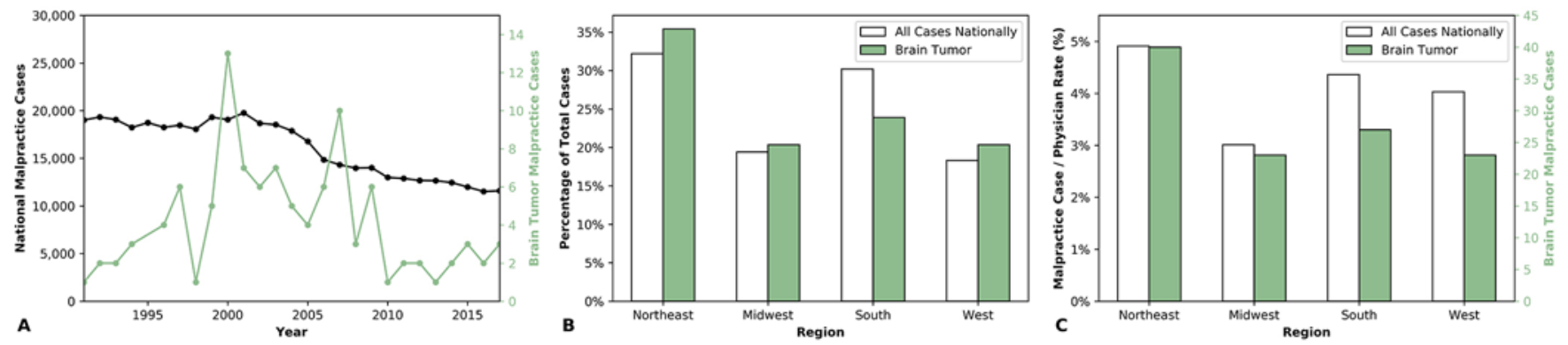

FIG. 2. Comparison between brain tumor and overall malpractice cases nationwide. A: Number of total malpractice cases nationwide in the NPDB (left y-axis) and brain tumor cases (right y-axis) in the study population from 1991 to 2017 ; 1991 was the starting year of malpractice data in the NPDB. B: Comparison of the percentage breakdown of total malpractice cases nationwide and brain tumor cases by Census region. C: Comparison of the malpractice case/physician rate for nationwide cases (left y-axis) and total number of brain tumor cases (right y-axis) for each Census region. 
Tang et al.
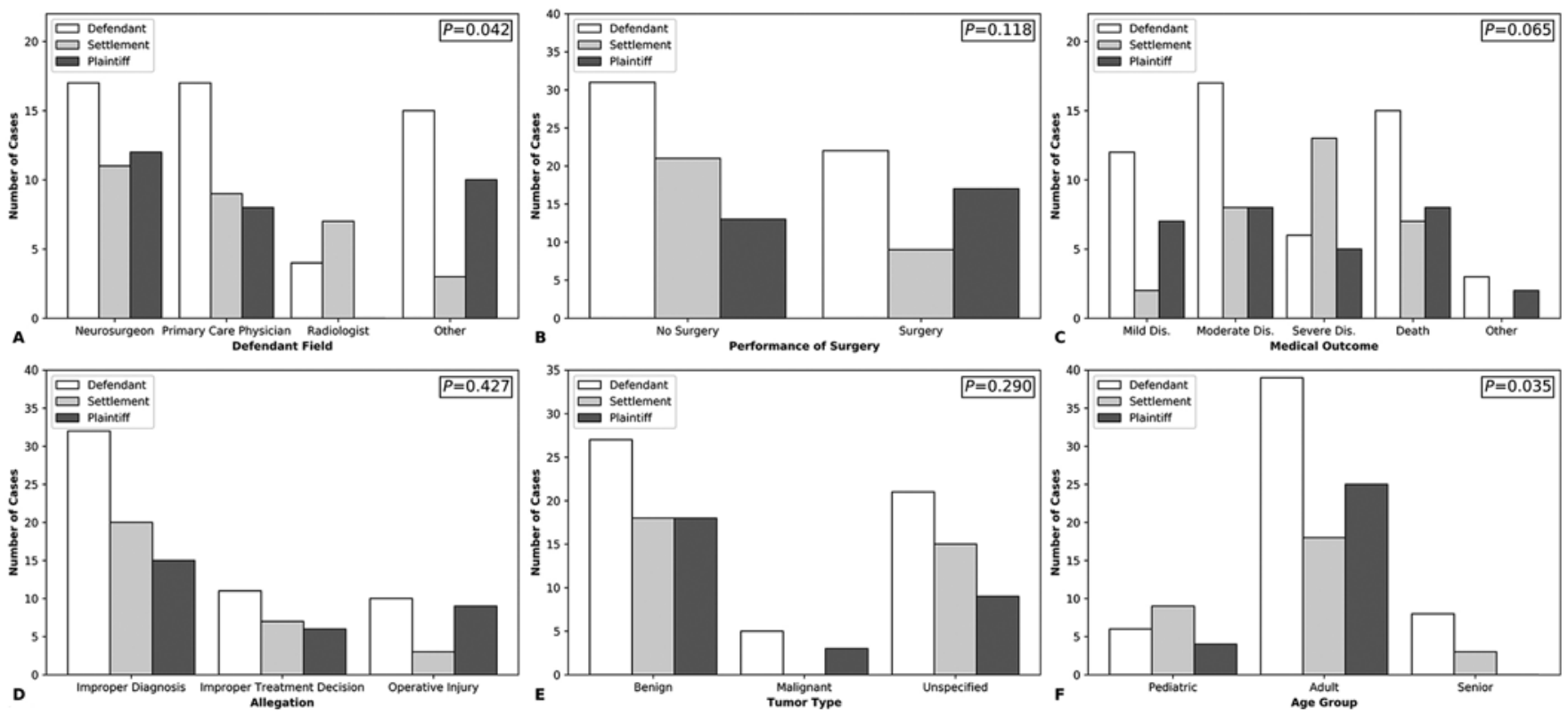

FIG. 3. Differences in litigation outcome based on the field of the primary defendant (A), whether the patient underwent surgery (B), medical outcome for the plaintiff (C), the plaintiff's allegation (D), tumor histopathology (E), and patient age group (F). Fisher's exact test was used to calculate the significance of differences in outcome depending on the studied variable. Dis. = disability.

TABLE 2. Univariate regression results for case outcome and indemnity payment levels

\begin{tabular}{|c|c|c|c|c|}
\hline Variable & OR for Case Outcome $(95 \% \mathrm{Cl})$ & $p$ Value & $\beta$-Coefficient for Payment $(95 \% \mathrm{Cl})$ & $\mathrm{p}$ Value \\
\hline \multicolumn{5}{|l|}{ Field of primary defendant (vs primary care) } \\
\hline Neurosurgeon & $0.74(0.29-1.85)$ & 0.519 & $2.33(1.17-4.66)$ & $0.017^{*}$ \\
\hline Radiologist & $0.57(0.14-2.32)$ & 0.433 & $1.28(0.48-3.39)$ & 0.617 \\
\hline Other & $1.15(0.42-3.14)$ & 0.779 & $1.13(0.51-2.51)$ & 0.761 \\
\hline Underwent surgery (vs no surgery) & $0.93(0.44-1.96)$ & 0.845 & $2.11(1.18-3.77)$ & $0.012^{*}$ \\
\hline \multicolumn{5}{|l|}{ Medical outcome (vs mild disability) } \\
\hline Moderate disability & $0.80(0.26-2.40)$ & 0.615 & $2.79(0.99-7.86)$ & 0.053 \\
\hline Severe disability & $0.25(0.08-0.89)$ & $0.032^{*}$ & $4.30(1.55-11.88)$ & $0.005^{*}$ \\
\hline Death & $0.75(0.24-2.30)$ & 0.615 & $1.98(0.69-5.65)$ & 0.203 \\
\hline Other & $1.125(0.15-8.21)$ & 0.908 & $1.69(0.24-11.83)$ & 0.598 \\
\hline \multicolumn{5}{|l|}{ Allegation (vs improper diagnosis) } \\
\hline Improper treatment decision & $0.92(0.36-2.36)$ & 0.871 & $1.48(0.70-3.13)$ & 0.306 \\
\hline Operative injury & $0.91(0.35-2.40)$ & 0.851 & $1.87(0.86-4.05)$ & 0.112 \\
\hline \multicolumn{5}{|l|}{ Tumor type (vs benign) } \\
\hline Malignant & $2.04(0.45-9.30)$ & 0.359 & $1.03(0.26-3.99)$ & 0.979 \\
\hline Unspecified & $1.07(0.49-2.32)$ & 0.865 & $1.64(0.90-3.00)$ & 0.107 \\
\hline \multicolumn{5}{|l|}{ Age group (vs pediatric) } \\
\hline Adult & $1.97(0.68-5.67)$ & 0.212 & $0.93(0.42-2.06)$ & 0.860 \\
\hline Senior & $5.78(1.12-29.85)$ & $0.036^{*}$ & $0.30(0.06-1.51)$ & 0.144 \\
\hline Case outcome for plaintiff (vs settlement) & NA & NA & $1.09(0.56-2.13)$ & 0.795 \\
\hline
\end{tabular}

NA = not applicable.

Univariate regression for predictors of case outcome (defendant vs settlement/plaintiff) or indemnity payment amount. Only cases with a settlement or plaintiff decision $(n=60)$ were included in the indemnity payment analysis. Odds ratios were reported for the case outcome, and $\beta$-coefficients were reported for indemnity payment amount. Case outcome (settlement vs plaintiff) was analyzed as an additional predictor for indemnity payment.

${ }^{*} p<0.05$. 


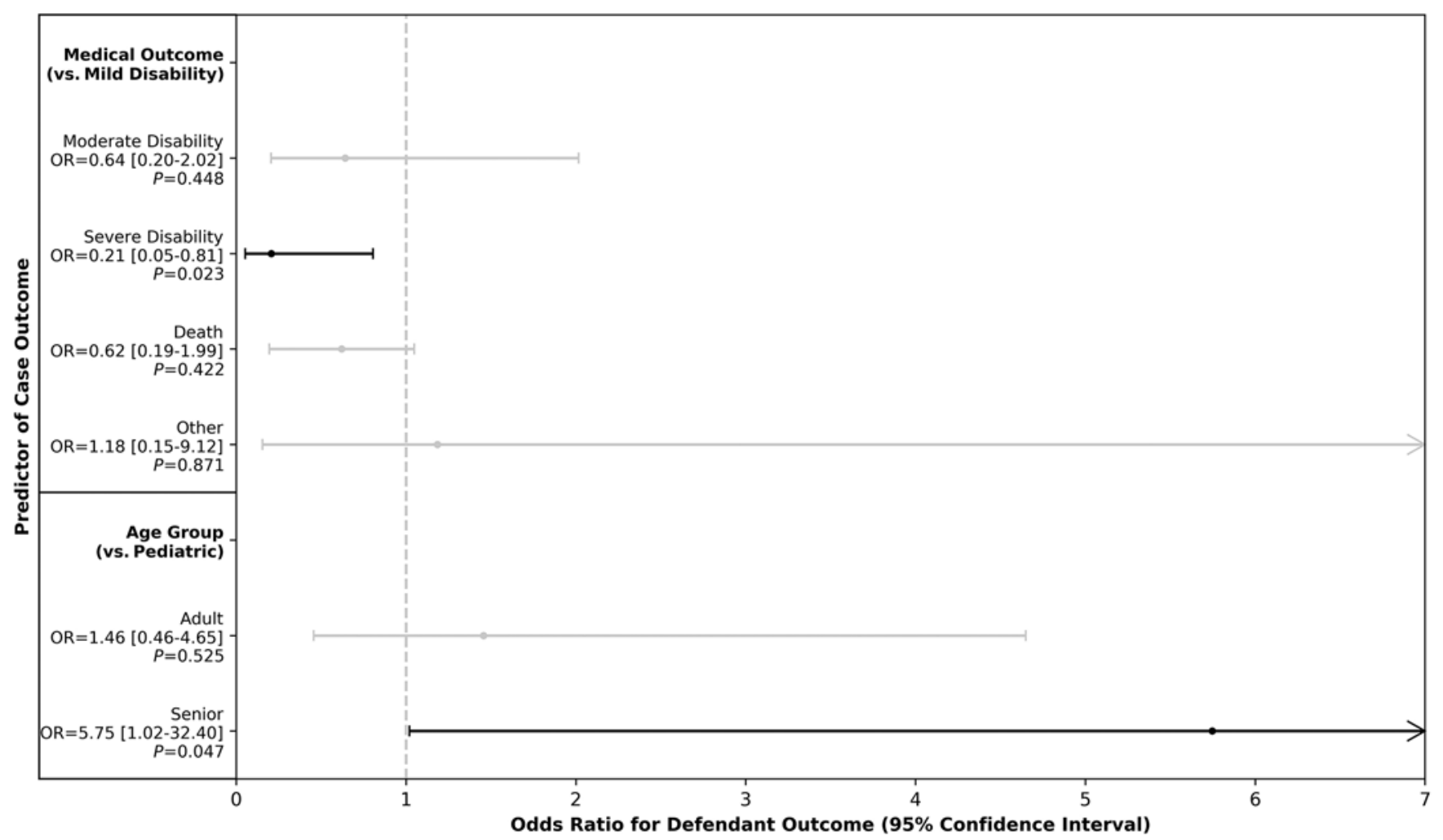

FIG. 4. Forest plot of odds ratios for predictors of defendant victory (instead of settlement or plaintiff victory) following multivariate regression.

ity (OR $0.21, \mathrm{p}=0.023)$ and senior age status (OR 5.75, $\mathrm{p}=0.047$ ) remained negatively and positively associated, respectively, with favorable litigation outcome for the defending physician (Fig. 4).

\section{Association Between Case Characteristics and Indemnity Payment}

Among the 60 cases resulting in an indemnity payment, while the highest mean payments were observed among neurosurgeon defendants $(\$ 4,736,754)$ and plaintiffs who underwent surgery $(\$ 4,549,730)$, these differences were not significant (Fig. 5A and B). However, indemnity payments did vary significantly between medical outcome categories $(\mathrm{p}=0.004)$, with plaintiffs who experienced severe disability $(\$ 5,020,335)$ and moderate disability $(\$ 3,254,493)$ receiving the highest average payments (Fig. $5 \mathrm{C}$ ). No significant differences in indemnity payment level were found by allegation, tumor type, or age group (Fig. 5D-F).

During univariate regression, factors that were associated with significantly higher indemnity payments included the defendant being a neurosurgeon ( $\beta$-coefficient $=2.33, \mathrm{p}=0.017)$, the plaintiff undergoing surgery $(\beta$-coefficient $=2.11, \mathrm{p}=0.012)$, and the plaintiff experiencing severe disability $(\beta$-coefficient $=4.30, p=0.005$; Table 2). When these three variables were included in multivariate regression, the only characteristic that remained significantly associated with indemnity payment level was medical outcome, with moderate disability $(\beta$-coefficient $=4.98, \mathrm{p}=0.007)$, severe disability $(\beta$-coefficient $=6.96, \mathrm{p}=0.001)$, and death $(\beta$-coefficient $=3.23, \mathrm{p}=0.027)$ all being predictive of elevated indemnity payments (Fig. 6 ).

\section{Discussion}

The present study represents an analysis of brain tumor malpractice litigation over nearly 3 decades and is, to the best of our knowledge, the first assessment of factors associated with case outcome and indemnity payment amount. This evaluation is important due to neurosurgery's status as the specialty most susceptible to malpractice claims. ${ }^{1}$ Additionally, because $23 \%$ of surveyed neurosurgeons by Smith et al. reported relinquishing their cranial surgery hospital privileges due to malpractice concerns, ${ }^{21}$ understanding risk factors related to malpractice litigation may inform efforts to preserve access to cranial procedures, including brain tumor resection.

Despite the southern United States having the highest volume of neurosurgery admissions, ${ }^{3}$ brain tumor malpractice claims were concentrated in New York and California. Although this may be due to the NPDB containing only a fraction of total cases, earlier assessments of brain aneurysms, ${ }^{22}$ spine surgery, ${ }^{15}$ and traumatic fracture have also corroborated that these two states have the highest caseload of malpractice cases. ${ }^{11}$ This geographic trend may be due to the greater density of hospitals and lawyers in these states and interstate legislative differences, such as the statute of limitations for filing a claim. These discrepancies may also 

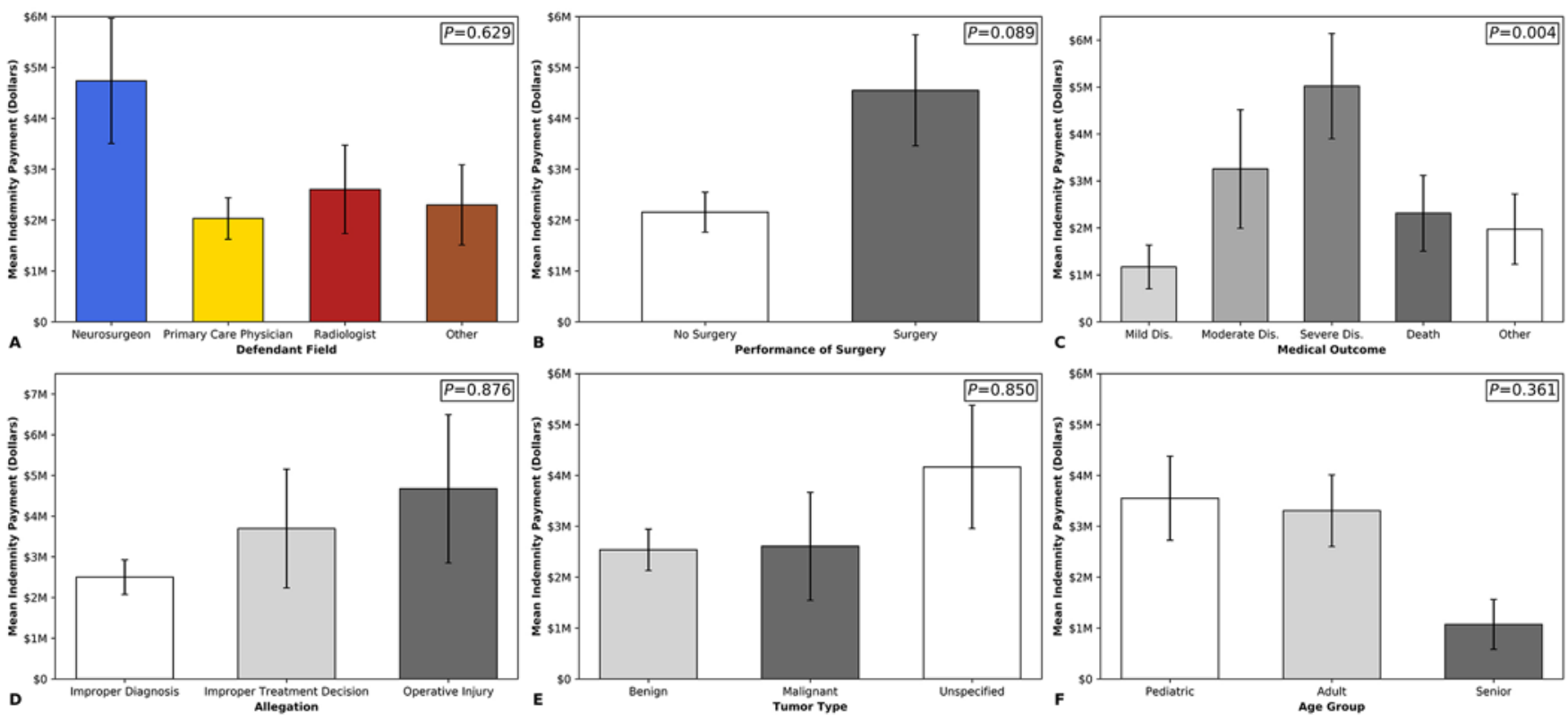

FIG. 5. Differences in indemnity payment level based on the field of the primary defendant (A), whether the patient underwent surgery (B), medical outcome for the plaintiff (C), the plaintiff's allegation (D), tumor histopathology (E), and patient age group (F). Nonparametric Mann-Whitney U-tests were used to calculate the significance of differences in indemnity payments depending on the studied variable.

be due to demographic differences; for example, patients of higher socioeconomic status have been shown to be $5-10$ times more likely to sue than patients of low socioeconomic status and uninsured patients. ${ }^{23,24}$ These geographic disparities may represent a potential risk factor for litigation that practicing neurosurgeons should be mindful of.

The distribution of specialties, allegations, and brain tumor subtypes among cases parallels the earlier findings of a similar national assessment by Kessler et al. of Westlaw, another legal database..$^{10}$ The most common specialty of primary defendants for brain tumor malpractice cases was neurosurgery, encompassing around one-third of cases. Additionally, as in the study by Kessler et al., the leading plaintiff allegation was improper diagnosis, followed by improper treatment decision and operative injury. Our findings further suggest that the breakdown of allegations varies significantly across fields, with improper diagnosis allegations concentrated among primary care physicians and radiologists, in contrast to cases involving treatment decision and operative injury disproportionately affecting neurosurgeons. Similarly, two national studies of neurosurgery malpractice claims found that improper performance accounts for a plurality of claims. ${ }^{2,4}$ One last similarity is that the majority of cases involved benign lesions. While this may reflect the higher overall incidence of low-grade brain tumors, the concentration of benign tumors in this study population may also be due to differing patient expectations regarding benign lesions, relative to malignancy. Nevertheless, a notable difference was that our study documented a substantially lower rate of defendant verdicts (46.9\%) compared with the study of Kessler et al. (70\%). While the rate documented by Kessler and colleagues was closer to the approximately $75 \%$ defendant victory rate reported across all medical malpractice trials, ${ }^{25}$ our findings parallel a national assessment by Thomas et al. for neurosurgery malpractice specifically, ${ }^{4}$ which estimated a $48.1 \%$ rate of defendant verdicts. Finally, across a comparable timeline, approximately 100 more brain tumor-related cases were identified in Westlaw; a similar difference has been documented for malpractice concerning stroke and spinal epidural abscesses. ${ }^{26,27}$ However, our use of VerdictSearch allowed us to characterize potential determinants of case outcome and indemnity payments.

We determined that the presence of a major disability reported by the plaintiff was associated with a significantly lower odds of defendant victory. Long-term postoperative sequelae, particularly neurological, have similarly been negative predictors of defendant victory for spine surgery ${ }_{15}^{15}$ incidental durotomies, ${ }^{12}$ spinal epidural abscesses, ${ }^{27,28}$ traumatic fracture, ${ }^{11}$ and arthroplasty. ${ }^{17}$ One study by DePasse et al. of spinal epidural abscesses suggested that disability may influence case outcome even if it is not a consequence of operative error, finding that paraplegic and quadriplegic patients were more likely to win in court, even if paralysis was documented preoperatively. ${ }^{28}$ The present findings reinforce the importance of clear and effective communication to patients regarding topics such as procedural risks, which has been shown to reduce instances of malpractice litigation. ${ }^{29,30}$ One suggestion from Bokshan et al. to this end is the increased development and utilization of procedure-specific consent forms,${ }^{17}$ such as those specific to the setting of tumor resection. Additionally, because the odds of defendant victory were only reduced for severe disability, complications may fall along a spectrum in terms of case outcome. While these findings may support the line of argument that malpractice litigation increases the quality of care by giving patients a mechanism to hold physicians account- 


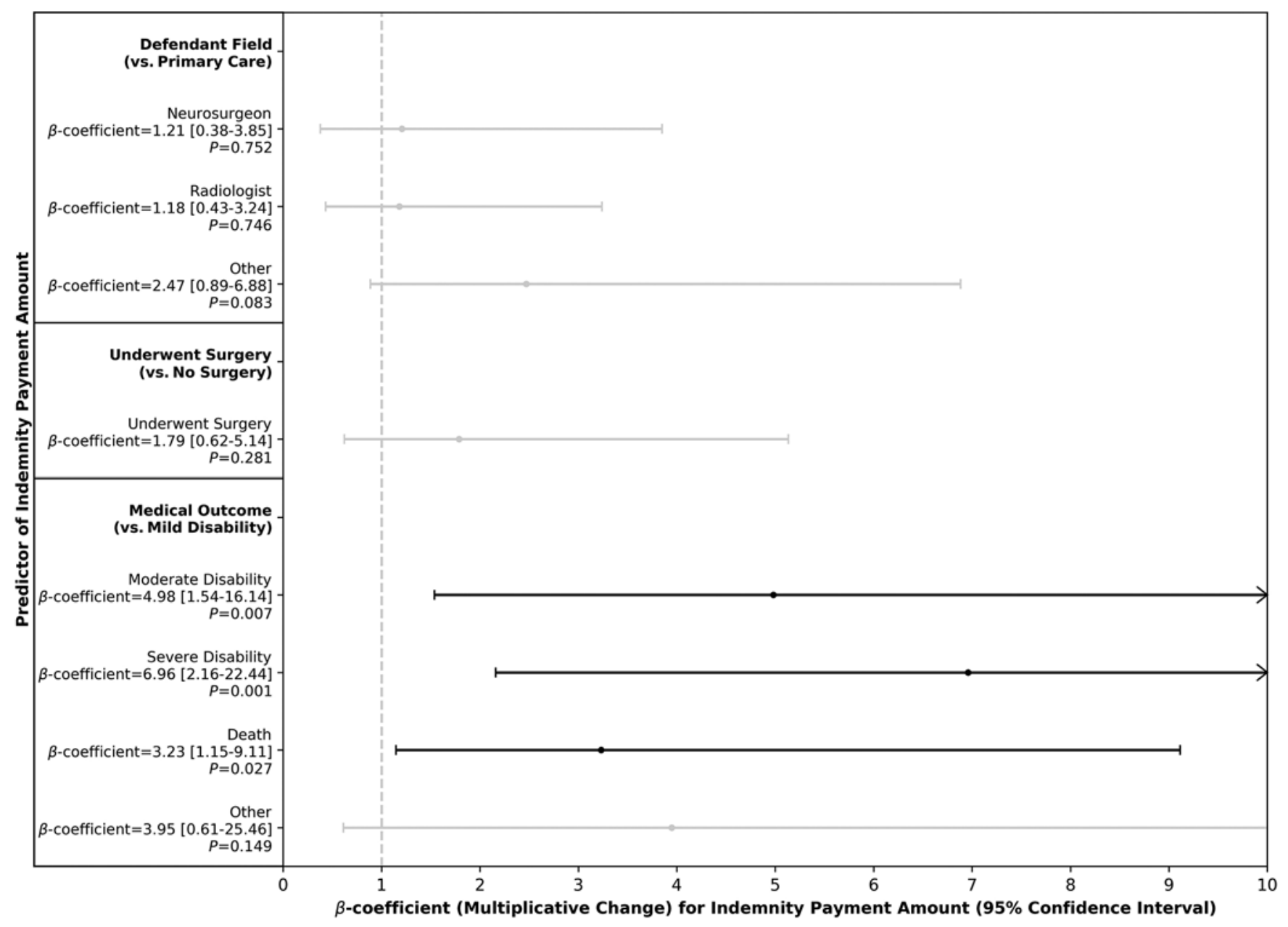

FIG. 6. Forest plot of $\beta$-coefficients for predictors of indemnity payment amount following multivariate regression. $\beta$-coefficients correspond to the percent change in indemnity payment amount (e.g., a $\beta$-coefficient $=1.90$ indicates a $90 \%$ increase compared with the reference group). Only cases resulting in a settlement or plaintiff victory were included for analysis.

able,$^{31}$ the lack of association between malpractice intensity and neurosurgical outcomes suggests that this may not bear out in practice..$^{32}$ We also found that plaintiffs older than 65 years had significantly lower rates of plaintiff victory compared with those younger than 18 years. This corroborates earlier findings not only for general neurosurgery, ${ }^{4}$ but also for head and neck cancer surgery and orthopedic procedures. ${ }^{18,33,34}$ The higher rate of defendant loss for cases involving pediatric plaintiffs may reflect the greater life expectancy or higher sympathy from the jury for these younger patients.

The present study also elucidates potential predictors of higher indemnity payments in cases resulting in plaintiff victory or settlement. While cases involving neurosurgical defendants, plaintiffs with a history of tumor resection, and reports of disability were associated with elevated payments on univariate analysis, only medical outcome (moderate disability, severe disability, or death) predicted higher indemnity payments during multivariate analysis. The association between medical outcome and indemnity payments may be due to this variable encapsulating factors like allegation severity and impairment, such as inability to return to work, that influence the settlement or adjudication process of a plaintiff's claim. One surprising finding was that there was no difference in indemnity payments between settlements and cases that ended in plaintiff victory, given that Thomas et al. determined that median payouts for plaintiff verdicts $(\$ 2,550,000)$ approximately doubled those for settlements $(\$ 1,300,000) .{ }^{4}$ Nevertheless, it is noteworthy that the indemnity payment incurred by a settlement does not reflect indirect costs, including bypassing a potentially lengthy legal process, with the costs and negative publicity associated with it. ${ }^{26,34}$ More research is warranted to characterize why there was not a difference in indemnity payments between these two case outcomes in the setting of brain tumor treatment.

\section{Study Limitations}

This present study has several potential limitations. First, like most legal databases, the VerdictSearch database is composed of cases that were electively submitted by case attorneys and passed editorial review. As exemplified by the sample size and limited geography, our study population represents only a small proportion of the to- 
tal brain tumor-related malpractice claims over the past 3 decades. Although VerdictSearch has been extensively used for medical malpractice research and we chose the database due to its depth of information related to indemnity payments, ${ }^{11-19}$ future investigations with larger sample sizes are warranted. Second, there was variable medical detail within cases because information within VerdictSearch was primarily legal in nature, as exemplified by one-third of the cases having insufficient data to classify tumor histopathology. Third, the detail contained in VerdictSearch cases may not fully encapsulate elements relevant to a case, such as physician-patient communication during the care process and deliberations outside the courtroom. Due to the highly individual nature of each malpractice claim, the present findings may not be applicable on a case-to-case basis. Nevertheless, this study is the first to characterize potential determinants of case outcome and indemnity payment amount in a nationwide cohort of brain tumor-related malpractice claims, and it elucidates potential risk factors that neurosurgeons should be mindful of when dealing with litigation.

\section{Conclusions}

Among 113 nationwide medical malpractice cases related to brain tumor treatment, $46.9 \%$ resulted in a verdict for the defendant. Neurosurgeons were most likely to be the primary defendant and had lower rates of favorable verdicts. Despite improper diagnosis being the most common allegation, neurosurgical defendants were more likely to have litigation brought against them for improper treatment decision or operative error. Patient medical outcome, such as disability or death, was a significant predictor of case outcome and indemnity payment amount. Cases involving juvenile plaintiffs were also less likely to result in a defendant verdict compared with those with elderly plaintiffs. Future research characterizing similar potential determinants of case outcome and indemnity payment levels for other neurosurgical procedures as well as reforms to reduce the burden of neurosurgical malpractice litigation is warranted.

\section{References}

1. Jena AB, Seabury S, Lakdawalla D, Chandra A. Malpractice risk according to physician specialty. $N$ Engl J Med.2011; 365(7):629-636.

2. Seabury SA, Chandra A, Lakdawalla DN, Jena AB. On average, physicians spend nearly 11 percent of their 40-year careers with an open, unresolved malpractice claim. Health Aff (Millwood). 2013;32(1):111-119.

3. Yoon JS, Tang OY, Lawton MT. Volume-cost relationship in neurosurgery: analysis of 12,129,029 admissions from the National Inpatient Sample. World Neurosurg. 2019;129:e791-e802.

4. Thomas R, Gupta R, Griessenauer CJ, et al. Medical malpractice in neurosurgery: a comprehensive analysis. World Neurosurg. 2018;110:e552-e559.

5. Baicker K, Fisher ES, Chandra A. Malpractice liability costs and the practice of medicine in the Medicare program. Health Aff (Millwood). 2007;26(3):841-852.

6. Ostrom QT, Gittleman H, Truitt G, et al. CBTRUS statistical report: primary brain and other central nervous system tumors diagnosed in the United States in 2011-2015. Neuro Oncol.2018;20(suppl_4):iv1-iv86.
7. Elsamadicy AA, Sergesketter AR, Frakes MD, Lad SP. Review of neurosurgery medical professional liability claims in the United States. Neurosurgery. 2018;83(5):997-1006.

8. Nahed BV, Babu MA, Smith TR, Heary RF. Malpractice liability and defensive medicine: a national survey of neurosurgeons. PLoS One. 2012;7(6):e39237.

9. Birkenbeuel J, Vu K, Lehrich BM, et al. Medical malpractice of vestibular schwannoma: a 40-year review of the United States legal databases. Otol Neurotol. 2019;40(3):391-397.

10. Kessler RA, Benzil DL, Loewenstern J, et al. malpractice litigation in brain tumor surgery: a 31-year analysis of causative factors in the United States from the Westlaw database. World Neurosurg. 2019;122:e1570-e1577.

11. Ahmed SA, DeFroda SF, Naqvi SJ, et al. Malpractice litigation following traumatic fracture. J Bone Joint Surg Am. 2019;101(7):e27.

12. Durand WM, Eltorai AEM, Shantharam G, et al. Medical malpractice claims following incidental durotomy due to spinal surgery. Spine (Phila Pa 1976). 2018;43(13):940-945.

13. Shah KN, Eltorai AEM, Perera S, et al. Medical malpractice litigation following arthroscopic surgery. Arthroscopy. 2018; 34(7):2236-2244.

14. Hartnett DA, Eltorai AEM, Osband AJ, et al. Cholecystectomy-related malpractice litigation: predictive factors of case outcome. Updates Surg. 2019;71(3):463-469.

15. Daniels AH, Ruttiman R, Eltorai AEM, et al. Malpractice litigation following spine surgery. J Neurosurg Spine. 2017; 27(4):470-475.

16. Deckey DG, Eltorai AEM, Jindal G, Daniels AH. Analysis of malpractice claims involving diagnostic and interventional neuroradiology. J Am Coll Radiol. 2019;16(5):764-769.

17. Bokshan SL, Ruttiman RJ, DePasse JM, et al. Reported litigation associated with primary hip and knee arthroplasty. $J$ Arthroplasty. 2017;32(12):3573-3577.e1.

18. DePasse JM, Sargent R, Fantry AJ, et al. Assessment of malpractice claims associated with acute compartment syndrome. J Am Acad Orthop Surg. 2017;25(6):e109-e113.

19. Bokshan SL, Ruttiman R, Eltorai AEM, et al. Factors associated with physician loss in anterior cruciate ligament reconstruction malpractice lawsuits. Orthop J Sports Med. 2017; 5(11):2325967117738957.

20. Singh H. National Practitioner Data Bank. Accessed September 14, 2020. https://www.npdb.hrsa.gov/analysistool/

21. Smith TR, Habib A, Rosenow JM, et al. Defensive medicine in neurosurgery: does state-level liability risk matter? Neurosurgery. 2015;76(2):105-114.

22. Gupta R, Griessenauer CJ, Moore JM, et al. An analysis of malpractice litigation related to the management of brain aneurysms. J Neurosurg. 2017;127(5):1077-1083.

23. Burstin HR, Johnson WG, Lipsitz SR, Brennan TA. Do the poor sue more? A case-control study of malpractice claims and socioeconomic status. JAMA. 1993;270(14):1697-1701.

24. McClellan FM, White AA III, Jimenez RL, Fahmy S. Do poor people sue doctors more frequently? Confronting unconscious bias and the role of cultural competency. Clin Orthop Relat Res. 2012;470(5):1393-1397.

25. United States Bureau of Justice Statistics. Medical Malpractice Trials. Accessed September 14, 2020. https://www.bjs. gov/index.cfm?ty $=$ tp \& $\mathrm{tid}=4511$

26. Haslett JJ, Genadry L, Zhang X, et al. Systematic review of malpractice litigation in the diagnosis and treatment of acute stroke. Stroke. 2019;50(10):2858-2864.

27. Shantharam G, DePasse JM, Eltorai AEM, et al. Physician and patients factors associated with outcome of spinal epidural abscess related malpractice litigation. Orthop Rev (Pavia). 2018;10(3):7693.

28. DePasse JM, Ruttiman R, Eltorai AEM, et al. Assessment of malpractice claims due to spinal epidural abscess. J Neurosurg Spine. 2017;27(4):476-480. 
29. Braddock CH III, Edwards KA, Hasenberg NM, et al. Informed decision making in outpatient practice: time to get back to basics. JAMA. 1999;282(24):2313-2320.

30. Levinson W, Roter DL, Mullooly JP, et al. Physician-patient communication. The relationship with malpractice claims among primary care physicians and surgeons. JAMA. 1997; 277(7):553-559.

31. Mello MM, Studdert DM, Brennan TA. The new medical malpractice crisis. N Engl J Med. 2003;348(23):2281-2284.

32. Bekelis K, Missios S, Wong K, MacKenzie TA. The practice of cranial neurosurgery and the malpractice liability environment in the United States. PLoS One. 2015;10(3):e0121191.

33. Oetgen ME, Parikh PD. Characteristics of orthopaedic malpractice claims of pediatric and adult patients in private practice. J Pediatr Orthop. 2016;36(2):213-217.

34. Simonsen AR, Duncavage JA, Becker SS. Malpractice in head and neck surgery: a review of cases. Otolaryngol Head Neck Surg. 2012;147(1):69-73.

\section{Disclosures}

The authors report no conflict of interest concerning the materials or methods used in this study or the findings specified in this paper.

\section{Author Contributions}

Conception and design: all authors. Acquisition of data: Hartnett, Hays. Analysis and interpretation of data: all authors. Drafting the article: Daniels, Tang, Hartnett, Hays. Critically revising the article: all authors. Reviewed submitted version of manuscript: all authors. Approved the final version of the manuscript on behalf of all authors: Daniels. Statistical analysis: Tang. Administrative/ technical/material support: Daniels. Study supervision: Daniels.

\section{Supplemental Information}

Online-Only Content

Supplemental material is available online.

Supplementary Table and Figure. https://thejns.org/doi/suppl/ 10.3171/2020.8.FOCUS20601.

\section{Correspondence}

Alan H. Daniels: Rhode Island Hospital, Providence, RI. alan_daniels@brown.edu. 